\title{
Edificios en altura másicos y livianos en ciudades-oasis: evaluación térmica y energética de viviendas debajo y sobre la copa de los árboles en Mendoza, Argentina
}

\author{
Heavy and light high-rise buildings in oasis-cities: thermal \\ and energy assessment of apartments above and below \\ the tree canopy in Mendoza, Argentina
}

\section{Julieta Balter \\ Carolina Ganem \\ Carlos Discoli}

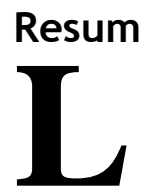

Resumen la misma. El objetivo del trabajo es evaluar la eficiencia energética y las condiciones de habitabilidad de unidades de viviendas en edificios en altura. Se seleccionaron cuatro casos en la Ciudad-Oasis de Mendoza, Argentina: dos ubicados debajo y dos sobre la copa de los árboles. Se evaluaron envolventes del tipo másica y liviana. Se realizaron durante dos años mediciones higro-térmicas in situ utilizadas para validar modelos mediante el programa de simulación Energy Plus. Se estudiaron medidas de rehabilitación energética y se analizaron comportamientos térmicos y consumos de energía para climatización. Los resultados demuestran que los departamentos debajo la copa de los árboles aprovechan en verano la protección de la arboleda urbana a la radiación incidente (diferencias térmicas del orden de $4^{\circ} \mathrm{C}$ ), y cuentan con temperaturas más elevadas en invierno (diferencias del orden de $3^{\circ} \mathrm{C}$ ). Con la materialidad edilicia mejorada, debajo la copa se logran consumos para climatización mínimos, cercanos a un edificio de energía cero. Asimismo, las viviendas de los edificios másicos demuestran comportamientos térmicos más cercanos al rango de confort respecto a los edificios livianos.

Palablas-claves: Ciudades-oasis. Bajo y sobre la copa de los árboles. Edificios en altura. Eficiencia energética. Materialidad másica y liviana.

\section{Abstract}

Julieta Balter

From an environmental point of view, the urban forest in Oasis-Cities defines two strata in height: one with a moderate microclimate under the trees, and a second one over the tree canopy that presents an extreme climatic situation. The aim of this study is to assess the energy efficiency and the conditions of habitability of apartments at different heights in high-rise buildings. Four case studies were selected in the Oasis-City of Mendoza, Argentina: two above and two under the tree canopy. Heavy and light envelopes were evaluated. For two years, in situ temperature measurements were taken in order to perform a diagnosis. These data were used to adjust and validate models using the dynamic Energy Plus software. We studied energy refurbishment strategies. Thermal behaviour and HVAC consumption were analysed. The results show that dwellings under the urban forest influence take advantage of solar radiation protection in summer (thermal differences of $4^{\circ} \mathrm{C}$ ), higher temperatures in winter (thermal differences of $3{ }^{\circ} \mathrm{C}$ ) and minimum consumption in HVAC systems, close to zero energy buildings. Furthermore, apartments in heavy buildings reported better thermal behaviour than those in light buildings.

Keywords: Oasis-cities. High-rise buildings. Above and below the tree canopy. Energy efficiency. Heavy and light materiality.

BALTER, J.; GANEM, C.; DISCOLI, C. Edificios en altura másicos y livianos en ciudades-oasis: evaluación térmica y energética de viviendas debajo y sobre la copa de los árboles en Mendoza, Argentina. Ambiente Construído, Porto Alegre, v. 16, n. 1, p. 39-54, jan./mar. 2016. 


\section{Introducción}

El consumo energético en el sector residencial es una de las grandes preocupaciones actuales a nivel mundial: compete cada vez a mayor cantidad de países, inclusive a los que se encuentran en vías de desarrollo. La energía requerida para climatización es el rubro de mayor importancia en las viviendas. Asimismo, la variación de la temperatura interior de diseño es otro factor que influye fuertemente en la demanda de energía (EVANS; SCHILLER, 2001).

En relación a la edificación en altura, muchas veces los proyectos no contemplan el entorno en el que van a ser construidos, y su morfología arquitectónica generalmente no involucra el aprovechamiento de los recursos naturales disponibles. Una situación característica de las tipologías edilicias en altura es que se encuentran arquitecturas similares en climas y geografías muy diversas. Es sorprendente que haya, aparentemente, una "única forma edilicia en altura" que repite en distintos lugares y climas una solución unívoca. Tal situación se evidencia cuando se analiza el uso de, por ejemplo, la tecnología denominada curtainwall o muro cortina. Dicho sistema fue originariamente planteado para un clima frío y húmedo localizado en una latitud elevada correspondiente a la ciudad de Nueva York $\left(40^{\circ} 41^{\prime} \mathrm{LN}\right)$ y hoy es replicado en forma constante alrededor del mundo desde Kuala Lumpur, Indonesia (clima cálido y húmedo, $3^{\circ} 08^{\prime}$ LN) hasta Mendoza, Argentina (clima templado y árido, $32^{\circ} 40^{\prime} \mathrm{LS}$ ).

Por otra parte, el panorama energético de los últimos años en Argentina motivó a distintos autores a evaluar las condiciones de habitabilidad y el consumo de energía en el sector edilicio. Los trabajos analizan las condiciones higrotérmicas y de confort interior, así como estrategias pasivas y activas de mejoramiento, mediante las cuales se logran reducir los consumos energéticos (VAGGE, FILIPPIN, CZAJKOWSKI, 2008; FILIPPIN, FLORES LARSEN, 2010; CZAJKOWSKI et al., 2012). Asimismo, en el año 2006 se desarrolla un modelo de ahorro de energía en refrigeración para edificios de habitación humana, junto a indicadores de eficiencia y valores admisibles propuestos al IRAM aplicables a tres tipos de edificios de vivienda (CZAJKOWSKI; CORREDERA, 2006). En relación al comportamiento energético ambiental de edificios residenciales en altura, un estudio busca conocer los valores para construir indicadores de consumo de energía real y mejorarlo, a fin de utilizarlo en un modelo a nivel urbano (SALVETTI; CZAJKOWSKI; GÓMEZ, 2009).
A nivel internacional, la problemática del consumo energético en el sector residencial ha sido también ampliamente analizada mediante propuestas de rehabilitación de la envolvente y otras medidas de ahorro (BOJIC; YIC, 2005; CHOA; YOOB; KIMC, 2014; LIU; RODHIN; MOSHFEGH, 2015). Algunos trabajos han diferenciado la materialidad de la envolvente en relación a su masividad y liviandad (PENG, 2010; PALME; ISALGUÉ; COCH, 2013). Estos estudios indican que las construcciones másicas, con altos niveles de inercia térmica, previenen fenómenos de sobrecalentamiento, aseguran niveles de confort, tienen un mejor desempeño energético y son una estrategia contundente para reducir el impacto del cambio climático en el ambiente construido.

Se observa que los trabajos mencionados, enfocados en los aspectos energéticos, térmicos y de materialidad de edificios en altura, consideran las características ambientales de los entornos en estudio. Sin embargo, ninguno de ellos se encuentra con un contexto inmediato de CiudadOasis, en donde se presenta una situación particular dada por dos estratos micro-climáticos claramente diferenciados, como es el caso de la ciudad de Mendoza (BÓRMIDA, 1984). Este tipo de ciudades, insertas en climas áridos, cuentan con beneficios ambientales provocados por la forestación urbana y definen dos escenarios:

Por un lado, la situación debajo la copa de los árboles beneficia a las edificaciones de baja altura (3 - 4 niveles) en verano ya que la radiación incidente es moderada e incluso puede ser bloqueada, dependiendo de la densidad del follaje (CANTÓN et al., 2003).Durante la noche en invierno las ramificaciones de los árboles protegen a las construcciones del frío. Por otra parte, fuera del estrato acondicionado, las edificaciones están expuestas directamente al clima de la región: la condición sobre la copa de los árboles consiente un acceso pleno a la radiación tanto en invierno (energía incidente deseada) como en verano (energía incidente no deseada) y una exposición al intercambio convectivo y radiativo de energías en ambas estaciones. Es así que este modelo de ciudad presenta un micro-clima que beneficia a las edificaciones de baja altura, atenuando la condicionante climática árida propia de la región. A pesar de tal diferenciación en el micro-clima, los edificios en altura tienden a lograr una imagen continua en toda su fachada, sin tener en cuenta los factores ambientales del entorno.

Por otra parte, la utilización de la masa térmica en las construcciones es un tema ampliamente estudiado (GIVONI, 1987; BALARAS, 1996).

40 Balter, J.; Ganem, C.; Discoli, C. 
Muchos estudios exponen que en regiones de climas áridos y templados resultan adecuadas las construcciones con materiales másicos con propiedades de inercia térmica debido a su comportamiento como reguladores térmicos. En el caso de la ciudad en estudio, la estructura (de hormigón armado) de las construcciones resulta significativa debido al alto potencial sísmico de la región. Esta situación, si bien favorece las posibilidades de regulación ambiental mediante la masa térmica del hormigón, se ve amenazada cuando se intenta reducir el costo de la estructura de los edificios en altura: el uso de materiales cada vez más delgados y livianos, tanto en la envolvente como en el interior de los edificios, responde a la búsqueda de alivianar dicha estructura. No obstante, en una ciudad sísmica como Mendoza, resultan necesarios materiales portantes $\mathrm{y}$, por ende, másicos

Por los motivos expuestos, la particularidad del contexto de las edificaciones en altura en Ciudades-Oasis, indican la necesidad de enfocar el estudio al análisis de la incidencia de la arboleda urbana en el desempeño térmico de viviendas según dos alturas: debajo y sobre la copa de los árboles. Por esto, el trabajo se centra en el impacto de dicha vegetación en los requerimientos energéticos. El objetivo del estudio es evaluar el comportamiento energético y térmico en unidades de vivienda ubicadas a diferentes alturas en edificios de materialidad másica y liviana en la ciudad de Mendoza. A partir del análisis de estaciones extremas auditadas in situ, se validan modelos de simulación dinámica mediante el programa Energy Plus. Con esto se propone establecer pautas y recomendaciones orientadas a fomentar mayores grados de sustentabilidad en edificios en altura en Ciudades-Oasis.

\section{Caso de estudio}

\section{Ciudad, clima y edificación en altura}

La ciudad de Mendoza, Argentina ( $32^{\circ} 40^{\prime}$ Latitud Sur, $68^{\circ} 51^{\prime}$ Longitud Oeste) si bien se emplaza en una zona originalmente semi-desértica y árida, se concibe como una "Ciudad-Oasis" (BÓRMIDA, 1984), caracterizándose por la coordinación de distintos factores: la estructura urbana en damero (es decir, una trama ortogonal de manzanas), la edificación, la forestación (trama de árboles que acompaña el trazado urbano) y un eficaz sistema de riego (acequias) que bordea el perímetro de las manzanas. Estos factores resultan en un estrato condicionado o sector de la atmósfera beneficiado ambientalmente por los efectos de la arboleda y el agua. Es así que este modelo de ciudad ha atenuado la condicionante climática árida propia de la región.

Respecto a las características climáticas, Mendoza presenta considerables diferencias en las temperaturas en las estaciones críticas, así como en sus amplitudes. En verano las temperaturas máximas absolutas se encuentran en $37,4^{\circ} \mathrm{C}$, y las máximas y mínimas medias son de $30,1^{\circ} \mathrm{C}$ y $18,4^{\circ} \mathrm{C}$ respectivamente. En invierno las mínimas absolutas son de $-5,7^{\circ} \mathrm{C}$, y las máximas y mínimas medias de $14,7^{\circ} \mathrm{C}$ y $3,4^{\circ} \mathrm{C}$. La radiación solar es típica de zonas semidesérticas, en la ciudad se registra un valor anual de $18,4 \mathrm{MJ} / \mathrm{m}^{2}$.día. La rigurosidad climática se acentúa debido al escaso porcentaje de humedad relativa anual $(54,7 \%)$. Asimismo las precipitaciones no superan los 218 mm anuales; y los vientos son suaves, con velocidades máximas en invierno de brisas que provienen del Sur, de $8 \mathrm{~km} / \mathrm{h}$; y en verano del SurOeste, de $15 \mathrm{~km} / \mathrm{h}$.

En cuanto al contexto edilicio, los edificios en altura residenciales construidos en Mendoza hasta mediados de siglo XX se caracterizan por contar en su envolvente con un $85 \%$ de materiales opacos como el ladrillo y el hormigón. Sin embargo, las tendencias arquitectónicas internacionales, orientadas al logro de una imagen liviana y transparente, se manifiestan actualmente en muchos de los edificios en altura, resultando notable el incremento del uso del vidrio en las nuevas construcciones: llegado el siglo XXI los materiales opacos en la envolvente disminuyen, con porcentajes que se encuentran en un $35 \%$, mientras que los transparentes representan el $65 \%$ (BALTER; GANEM; CANTÓN, 2013). Tal contexto dificulta las posibilidades de mantener temperaturas de confort interior sin el uso de medios mecánicos de climatización para enfriamiento, significando esto grandes consumos de energía. Así mismo, acerca de la consideración de "edificio en altura" en Mendoza, el carácter sísmico de la región contribuyó a la regulación de alturas máximas, por lo que hasta el año 2000 aproximadamente, en la mayoría de los casos, los edificios no superaban los 8 niveles (25 metros). Si bien en los últimos años las alturas han aumentado - debido a excepciones al código de edificación-, y esta es una tendencia en crecimiento, todavía son escasos los edificios que alcanzan los 20 niveles de altura. 


\section{Selección de edificios y unidades de vivienda}

Los edificios en estudio se encuadran en el contexto de manzanas urbanas de alta densidad del Área Metropolitana de Mendoza.

A los efectos de evaluar la condición más favorable desde el punto de vista bioclimático (en el hemisferio Sur) se selecciona la orientación Norte y unidades de departamentos frontales dada su relación directa con dicha orientación, a los canales viales (calle San Lorenzo y calle Rivadavia, de $20 \mathrm{~m}$ de ancho) y por ende a la forestación urbana (Moreras de $12 \mathrm{~m}$ de altura).

Se seleccionan dos edificios que cuentan con diferentes materializaciones de envolventes másica y liviana - a partir de determinar los siguientes índices:

(a) tipología másica: construcciones que presentan en su envolvente vertical más del $50 \%$ de materiales con densidad $(\rho)$ por metro cúbico mayor o igual a $1200 \mathrm{~kg} / \mathrm{m}^{3}$, y un peso por metro cuadrado mayor o igual a $100 \mathrm{~kg} / \mathrm{m}^{2}$; y

(b) tipología liviana: construcciones que cuentan en su envolvente vertical con más del $50 \%$ de materiales con densidad $(\rho)$ por metro cúbico menor a $1200 \mathrm{~kg} / \mathrm{m}^{3}$, y un peso por metro cuadrado menor a $100 \mathrm{~kg} / \mathrm{m}^{2}$.

En relación a las unidades de vivienda se analizan por edificio dos departamentos equivalentes entre sí (igual superficie, diseño, orientación y ubicación en la fachada), pero en distintas alturas por edificio. De acuerdo con la particular estructura de "Ciudad-Oasis" de Mendoza se realiza la siguiente clasificación definida en este trabajo:

(a) viviendasbajo la copa de los árboles: hasta el $3^{\circ}$ nivel, correspondiente a los $12 \mathrm{~m}$ de altura máxima; y

(b) viviendas sobre la copa de los árboles: a partir del $4^{\circ}$ nivel.

El edificio másico (Figura 1) responde a la tipología en Torre adosada a las líneas divisorias de edificación, es decir, que la construcción no se retira de los límites del terreno. Cuenta con un $73 \%$ de materiales opacos en su envolvente y la resistencia térmica media de envolvente total es de $0,49 \mathrm{~m}^{2}{ }^{\circ} \mathrm{C} / \mathrm{W}$. La materialidad del edificio es de ladrillos cerámicos huecos de $0,30 \mathrm{~m}$ de espesor con revoque y pintura al exterior, sin aislación, ( $\mathrm{K}$ $=1,36 \mathrm{~W} / \mathrm{m}^{2}{ }^{\circ} \mathrm{C}$ ) y las divisiones interiores son del mismo material de $0,10 \mathrm{~m}$ de espesor $(\mathrm{K}=$ $\left.1,97 \mathrm{~W} / \mathrm{m}^{2 \circ} \mathrm{C}\right)$. Las cubiertas son de losa nervada con ladrillo hueco y aislación $\left(\mathrm{K}=0,24 \mathrm{~W} / \mathrm{m}^{2}{ }^{\circ} \mathrm{C}\right)$. Los vidrios son simples de $4 \mathrm{~mm}$ de espesor $(\mathrm{K}=$ $5,8 \mathrm{~W} / \mathrm{m}^{2 \circ} \mathrm{C}$, factor solar $\left.=0,87\right)$. En cuanto a elementos de protección solar cuenta con balcones de $1,20 \mathrm{~m}$ de profundidad y persianas corredizas con celosías de madera color blanco.

Las unidades de vivienda monitoreadas, tienen una superficie cubierta de $122,50 \mathrm{~m}^{2}$ y semi-cubierta (balcón) de $5,50 \mathrm{~m}^{2}$ y se ubican en el primer y quinto nivel.

Figura 1 - Edificio másico. Fachada (Norte), planta general y planta de la unidad de vivienda en estudio
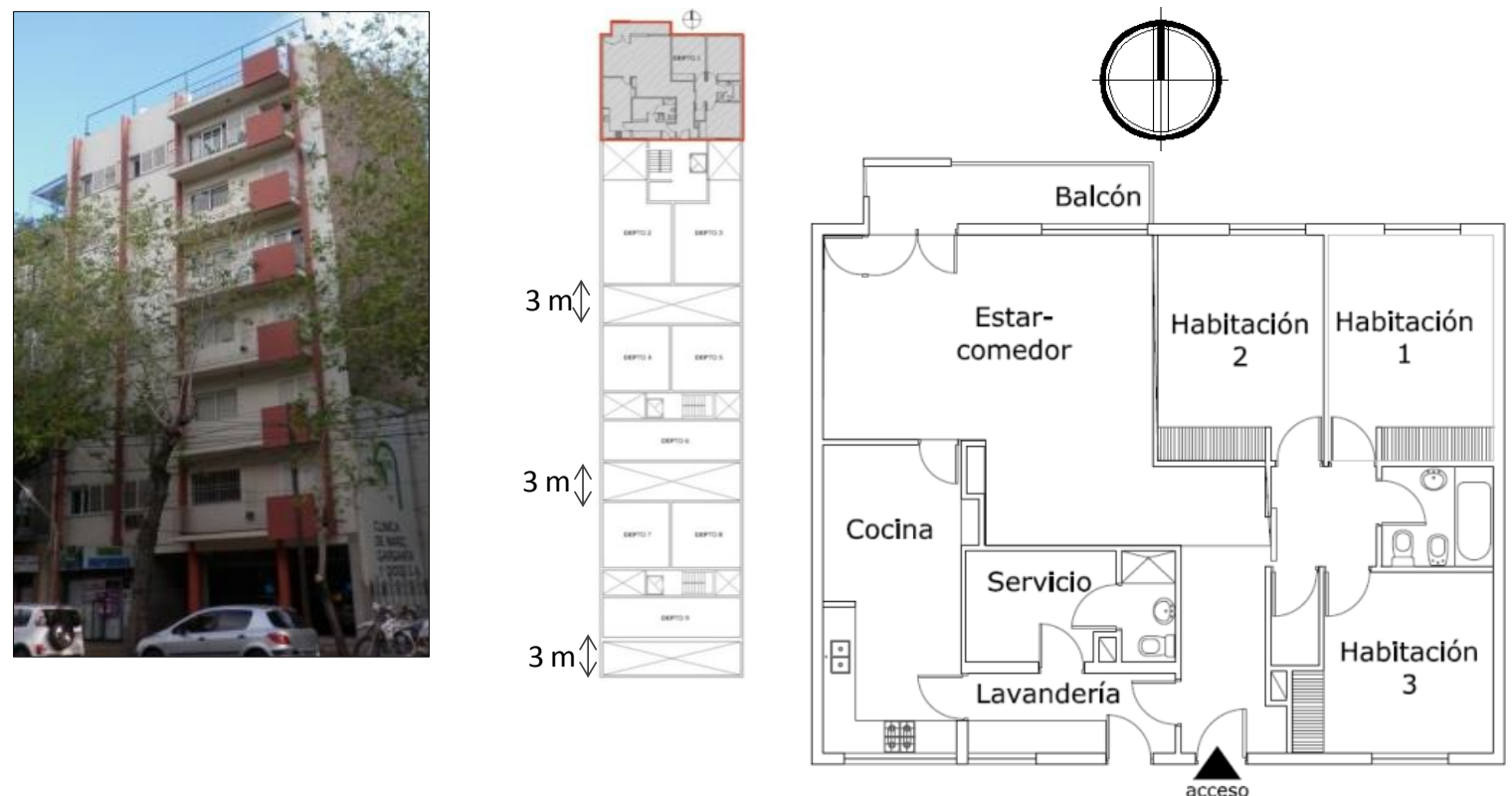

42 Balter, J.; Ganem, C.; Discoli, C. 
El edificio liviano (Figura 2) responde a la tipología de Torre retirada de las líneas divisorias de edificación (retiro frontal de 5 metros, laterales de 6 metros y posterior de 15 metros). Respecto a la materialidad responde a la concepción de edificio de estructura de hormigón y piel de vidrio, y si bien la estructura resulta significativa debido al carácter sísmico de la región, predomina una estética trasparente. Cuenta con un $76 \%$ de materiales trasparentes en su envolvente y la resistencia térmica media de envolvente total es de $0,26 \mathrm{~m}^{2 \circ} \mathrm{C} / \mathrm{W}$. Los muros en la envolvente son de hormigón armado con revoque texturado con base de polímero $\left(\mathrm{K}=2,55 \mathrm{~W} / \mathrm{m}^{2 \circ} \mathrm{C}\right)$, y en el interior las divisiones son livianas, de tabiques de cartón y yeso tipo Durlock, de $10 \mathrm{~cm}$ de espesor ( $\mathrm{K}=$ $\left.5,70 \mathrm{~W} / \mathrm{m}^{2 \circ} \mathrm{C}\right)$. Las losas son $\mathrm{de}^{\circ} \mathrm{H}^{\circ} \mathrm{A}^{\circ}(\mathrm{K}=2,40$ $\mathrm{W} / \mathrm{m}^{2 \circ} \mathrm{C}$ ) y los vidrios son vidrios laminados de 6 $\mathrm{mm}(3+3)\left(\mathrm{K}=5,7 \mathrm{~W} / \mathrm{m}^{2 \circ} \mathrm{C}\right.$ factor solar $\left.=0,07\right)$ con láminas de polivinil butiral (PVB) de 0,38 aplicadas con calor y presión con tramos incoloros, artic-bluey espejados. El edificio cuenta con balcones de $1 \mathrm{~m}$ de profundidad, y ningún tipo de elementos de protección solar en la envolvente.

Las unidades de vivienda cuentan con una superficie cubierta de $98 \mathrm{~m}^{2}$ y semi-cubierta (balcón) de $17 \mathrm{~m}^{2}$ y se ubican en los niveles tercero y dieciséis.

\section{Metodología}

\section{Auditorías termo-energéticas}

Se efectuaron mediciones de temperatura y humedad relativa simultáneamente en los cuatro casos en estudio (dos departamentos por edificio: debajo y sobre la copa de los árboles) en las cuatro estaciones del año durante períodos entre veinte y treinta días por dos años. Se utilizaron microadquisidores de datos de temperatura y humedad HOBO U.12 de la marca ONSET con intervalos de registro cada 15 minutos simultáneos en todos los instrumentos. Este criterio fue adoptado de acuerdo a las recomendaciones de Longobardi y Hancock (2000). Las mediciones de radiación solar global se realizan con un Solarímetro CM 5 KIPP \& ZONEN en los mismos períodos y con la misma frecuencia de toma de datos establecida para las mediciones de temperatura de aire $\mathrm{y}$ humedad.

A los efectos de analizar los requerimientos energéticos anuales de los departamentos en estudio se obtuvieron las facturas bimestrales de gas natural y electricidad, coincidente con los períodos en los que se auditaron las condiciones térmicas. Se diferenciaron los consumos para climatización para invierno y verano a partir de los siguientes criterios:

(a) climatización en invierno: se calculó el promedio de los consumos de gas natural en los períodos que no se utilizan sistemas de calefacción (de setiembre a mayo). Con este dato se obtiene el consumo para agua caliente y cocción en el periodo de invierno, pudiendo diferenciar de este modo el consumo para calefacción; y

(b) climatización en verano: se calculó el promedio de los consumos de electricidad en los períodos que no se utilizan sistemas de enfriamiento. Con este dato se obtiene el consumo para iluminación y electrodomésticos en el periodo de verano, pudiendo diferenciar de este modo el consumo para refrigeración. En este caso se diferencian las viviendas másicas de las livianas, dado que en las últimas (livianas) se utilizan medios de enfriamiento en períodos más extensos.

Figura 2 - Edificio liviano. Fachada (Nor-Oeste), planta general y planta de la unidad de vivienda en estudio
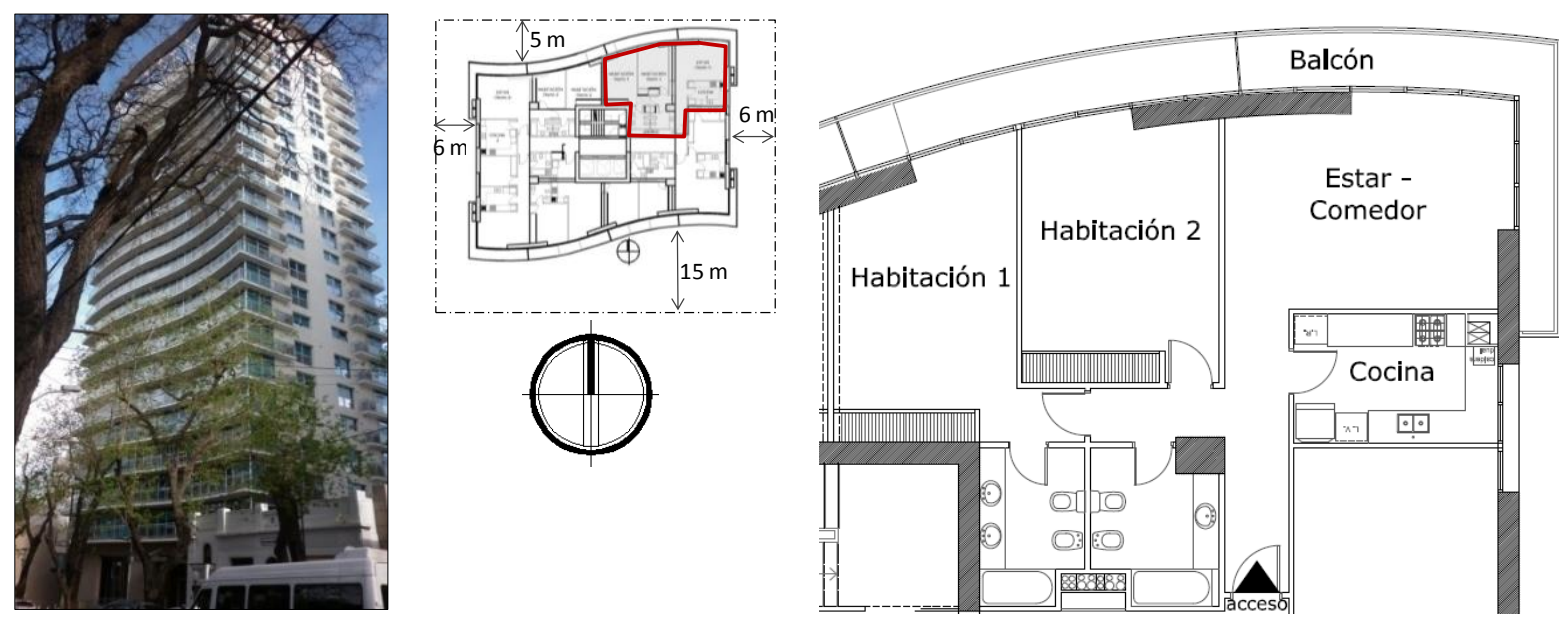
Las auditorías se complementaron con entrevistas abiertas a los habitantes con el objetivo de conocer el uso y ocupación de los espacios (horarios, gestión de la envolvente, uso de medios mecánicos de climatización, etc.). Esto hizo posible poder explicar variaciones térmicas y en los niveles de consumo en casos con características constructivas equivalentes.

Con el fin de contar con una referencia clara de los casos en estudio se definen las siguientes abreviaturas:

MS: vivienda sobre la copa de los árboles del edificio másico;

MB: vivienda bajo la copa de los árboles del edificio másico;

LS: vivienda sobre la copa de los árboles del edificio liviano; $\mathrm{y}$

LB: vivienda bajo la copa de los árboles del edificio liviano.

\section{Validación de modelos de simulación}

El método de validación de instrumentos de abordaje relacionados con el audit-diagnóstico y su ajuste mediante simulaciones dinámicas ha sido desarrollado en numerosos estudios a partir de programas tales como Energy Plus (BALLARINI; CORRADO, 2012; BURATTI et al., 2013) o TRNSYS (TERZIOTTI; SWEET; MCLESKEY, 2012; TERÉS-ZUBIAGA et al., 2015). Esta metodología permite ensayar y evaluar el estado del arte de la edilicia en cuestión y generar múltiples propuestas de mejoras diseñadas en laboratorio.

En el presente trabajo las mediciones fueron utilizadas para validar modelos de simulación dinámica mediante el programa Energy Plus, versión 8.1. Este programa de simulación térmica y energética de edificios ha sido desarrollado por U.S Department of Energy (2014), a partir de códigos de BLAST y DOE2 (SCARDUELLI; WESTPHAL; LAMBERTS, 2005).

Con las variables climáticas medidas en los períodos seleccionados, se conformó el archivo de clima requerido para la simulación de los modelos. Los datos necesarios son: radiación global sobre superficie horizontal, radiación difusa sobre superficie horizontal, radiación directa normal al haz, temperatura de bulbo seco exterior, humedad relativa exterior, velocidad y dirección de vientos. La radiación directa al haz y difusa sobre plano horizontal se calculan por medio de un módulo de cálculo anexo al SIMEDIF (FLORES LARSEN et al., 2000) ingresando la radiación global sobre superficie horizontal y los datos geográficos del lugar.

En este estudio se realizaron dos archivos climáticos: uno, para la condición dada sobre la copa de los árboles, que contiene las mediciones realizadas de temperaturas y radiación solar global; $\mathrm{y}$ un segundo archivo en el cual se modifica la radiación incidente bajo la arboleda urbana a fines de contemplar la situación debajo la copa de los árboles. Para ello se tienen en cuenta los estudios realizados sobre el grado de permeabilidad de árboles en ciudades del centro oeste de Argentina (CANTÓN et al., 2003). Dicha permeabilidad a la radiación global al mediodía solar correspondiente a la arboleda urbana existente en el caso de estudio (Morus Alba) es del 31,4\% en verano y del 66,4\% en invierno.

\section{Intervención tecnológica de la envolvente}

Se estudiaron distintas propuestas de mejoras de la materialidad vertical opaca y transparente, con el fin de seleccionar las variables constructivas convenientes en los casos analizados.

En el caso másico se selecciona una envolvente opaca de ladrillo macizo de $0,25 \mathrm{~m}$ con aislación de poliuretano expandido de $0,05 \mathrm{~m} \quad(\mathrm{~K}=0,78$ $\mathrm{W} / \mathrm{m}^{2 \circ} \mathrm{C}$ ), y en el caso liviano se continúa trabajando con una envolvente opaca de hormigón armado de $0,40 \mathrm{~m}\left(\mathrm{~K}=2,54 \mathrm{~W} / \mathrm{m}^{2}{ }^{\circ} \mathrm{C}\right)$. En ambos edificios la envolvente transparente seleccionada es doble vidriado hermético (DVH) de $6 \mathrm{~mm}$ con cara interior de baja emisividad $\left(\mathrm{K}=1,80 \mathrm{~W} / \mathrm{m}^{2}\right.$ $\left.{ }^{\circ} \mathrm{C}\right)$.

\section{Comparación de resultados termo- energéticos}

Con el objetivo de analizar las respuestas térmicas y energéticas de acuerdo a las diferencias en altura y materialidad se tuvieron en cuenta dos aspectos: por un lado, en relación al uso y ocupación de los espacios, se simularon los comportamientos térmicos excluyendo la incidencia de los usuarios, es decir considerando a las viviendas desocupadas $\mathrm{y}$ sin ganancias internas.

$\mathrm{Y}$ por otro lado, se modificaron y unificaron las tipologías morfológicas con el fin de analizar las respuestas dadas debajo y sobre la copa de los árboles. El Código de Edificación de Mendoza (MUNICIPALIDAD..., 2010) define dos tipologías: la de "Basamento y torre" y la de "Torre retirada". El Basamento se considera a la construcción que puede desarrollarse hasta los límites del terreno (sin retiros) con una altura máxima de 10m; y por Torre se entiende a las

44 Balter, J.; Ganem, C.; Discoli, C. 
construcciones con retiros de los límites del terreno en todo su perímetro, pudiendo alcanzar alturas máximas en relación a las dimensiones del predio.

Los casos a analizar son los siguientes (Figura 3):

(a) bajo la copa de los árboles $\left(1^{\circ}\right.$ nivel $)$ :

- tipología de Basamento y torre; y

- tipología de Torre retirada ${ }^{1}$.

(b) sobre la copa de los árboles (condiciones equivalentes en ambas tipologías):

- nivel medio ( $5^{\circ}$ nivel); y

- nivel alto ( $16^{\circ}$ nivel).

Debido a que la atmósfera cambia con la altitud y que la velocidad del viento aumenta con la altitud, los edificios altos pueden experimentar diferencias significativas en las propiedades atmosféricas locales entre la planta baja y la planta superior (UNITED..., 2014). El programa Energy Plus calcula la temperatura del aire exterior según la altura según la siguiente fórmula (Ec.1):

$T_{z}=T_{b}+L\left(H_{z}-H_{b}\right)$

Ec. 1

Dónde:

$\mathrm{T}_{\mathrm{z}}=$ temperatura del aire en la altitud $\mathrm{z} ;$

$\mathrm{T}_{\mathrm{b}}=$ temperatura del aire en la troposfera ;

$\mathrm{L}=$ gradiente de temperatura del aire $(-0,0065 \mathrm{~K} /$ $\mathrm{m}$ en la troposfera);

$\mathrm{H}_{\mathrm{b}}=$ cero para la troposfera; $\mathrm{y}$

$\mathrm{H}_{\mathrm{z}}=$ altitud geopotencial (altura sobre el nivel del piso). Se define por (Ec.2):

$\mathrm{H}_{z}=\frac{E z}{(E+z)}$

Dónde:

$\mathrm{E}=6.356 \mathrm{~km}$ (radio de la Tierra); $\mathrm{y}$

$\mathrm{z}=$ altura.

Para calcular la velocidad del viento según la altura el programa tiene en cuenta la siguiente fórmula (Ec. 3):

$V_{z=} V_{m e t}\left(\frac{\delta_{m e t}}{z_{m e t}}\right)^{\alpha_{m e t}}\left(\frac{Z}{\delta}\right)^{\alpha}$

Ec. 3

Dónde:

$\mathrm{z}=$ altura (sobre el suelo);

${ }^{1} \mathrm{El}$ primer nivel $\left(1^{\circ}\right)$ de la tipología de Torre retirada no cuenta con la protección de la arboleda urbana debido al retiro frontal obligatorio. Los niveles $5^{\circ}$ y $16^{\circ}$-sobre la copa de los árbolesresultan equivalentes en ambas tipologías al no contar con edificaciones colindantes debido a la obligatoriedad de retiros laterales y posteriores en las torres. Es decir, que sus condiciones térmicas interiores no se verían afectadas en relación a la diferenciación tipológica.
$\mathrm{V}_{\mathrm{z}}=$ velocidad del viento en la altura $\mathrm{z}$;

$\alpha=$ velocidad del viento exponente en el sitio;

$\delta=$ velocidad de viento de la capa límite en el sitio;

$\mathrm{Z}_{\text {met }}=$ altura sobre el suelo de velocidad del viento en la estación meteorológica;

$\mathrm{V}_{\text {met }}=$ velocidad del viento medida en la estación meteorológica;

$\alpha_{\text {met }}=$ velocidad del viento exponente en la estación meteorológica; y

$\delta_{\text {met }}=$ velocidad de viento de la capa límite en la estación meteorológica.

Los coeficientes de velocidades $\alpha$ y $\delta$ son variables que dependen de las características de rugosidad del terreno circundante (AMERICAN..., 2005).

\section{Auditorías térmicas y energéticas}

\section{Verano}

En eledifico másico (Tabla 1) las temperaturas de las dos viviendas analizadas cuentan con valores medios del orden de $28^{\circ} \mathrm{C}$, tanto en el estar como en las habitaciones, debido a las condiciones de uso y gestión de la envolvente: en el caso MS los usuarios cierran cortinas durante el día moderando la radiación incidente, mientras que en el caso $\mathrm{MB}$ no se cierran cortinas. Sin embargo, la arboleda urbana modera la radiación incidente en la vivienda bajo la copa de los árboles, por lo que las temperaturas interiores resultan similares en ambos casos.

En el edificio liviano (Tabla 1) las temperaturas medias interiores en las dos viviendas son similares (de $29,3^{\circ} \mathrm{C}$ en el estar y $27^{\circ} \mathrm{C}$ en las habitaciones) debido a la morfología del edificio de torre retirada, en donde el caso LB no se beneficia de la moderación a la radiación de la arboleda urbana. Asimismo, el caso LS, ubicado en el nivel 16, cuenta con mayores diferencias térmicas diarias $\left(\Delta \mathrm{T}\right.$ de $3^{\circ} \mathrm{C}$ en el estar y $1,5^{\circ} \mathrm{C}$ en la habitación) debido a las condiciones atmosféricas dadas en altura.

En cuanto a las auditorías energéticas (Figura 4a) los departamentos del edificio liviano presentan consumos para climatización más elevados - 2.9 $\mathrm{kWh} / \mathrm{m}^{2}$ para el caso LB y $2.7 \mathrm{kWh} / \mathrm{m}^{2}$ para LS -; mientras que en el edificio másico los consumos son menores - $0.3 \mathrm{kWh} / \mathrm{m}^{2}$ en $\mathrm{MB}$ y $0.2 \mathrm{kWh} / \mathrm{m}^{2}$ en MS. 
Figura 3 - Niveles de análisis en las tipologías morfológicas en estudio

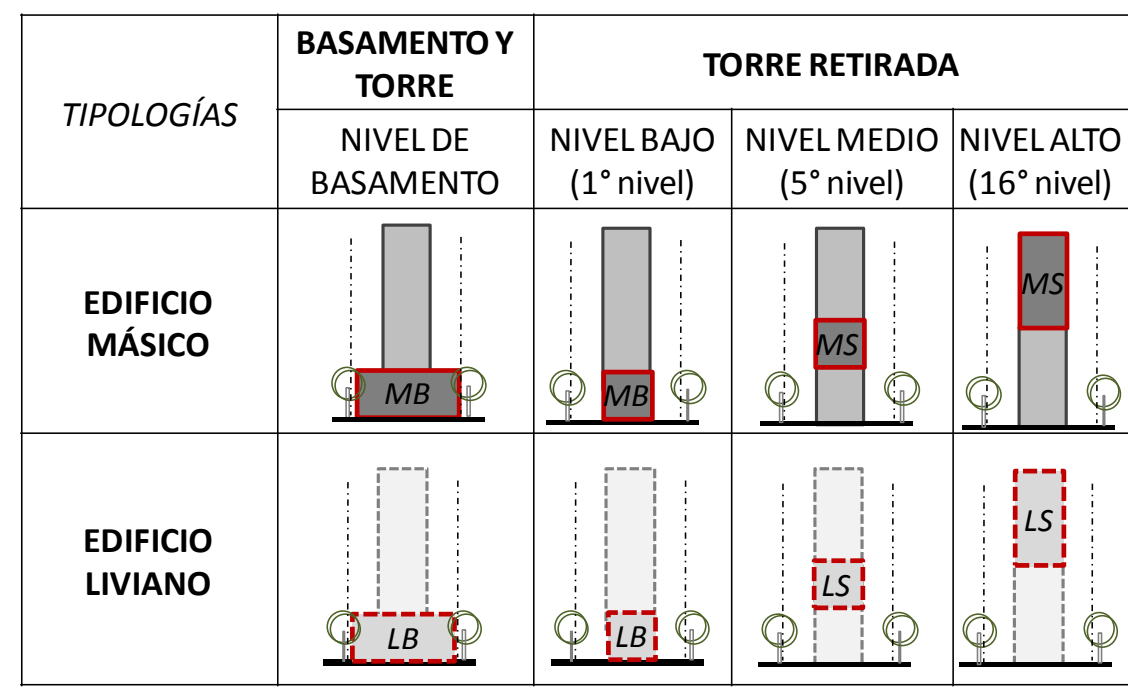

Tabla 1 - Temperaturas interiores y exterior en verano en los cuatro casos de estudio

\begin{tabular}{c|c|c|c|c|c|c}
\hline \multicolumn{6}{c}{ TEMPERATURAS DE VERANO } \\
\hline \multirow{3}{*}{ Casos } & \multicolumn{2}{|c|}{ Estar } & \multicolumn{2}{c}{ Habitación } & \multicolumn{2}{c}{ EXTERIOR } \\
\cline { 2 - 6 } & $\begin{array}{c}\text { Temp. Media } \\
{\left[{ }^{\circ} \mathrm{C}\right]}\end{array}$ & $\begin{array}{c}\Delta \mathrm{T} \text { diario } \\
{\left[{ }^{\circ} \mathrm{C}\right]}\end{array}$ & $\begin{array}{c}\text { Temp. Media } \\
{\left[{ }^{\circ} \mathrm{C}\right]}\end{array}$ & $\begin{array}{c}\Delta \mathrm{T} \text { diario } \\
{\left[{ }^{\circ} \mathrm{C}\right]}\end{array}$ & $\begin{array}{c}\text { Temp. Media } \\
{\left[{ }^{\circ} \mathrm{C}\right]}\end{array}$ & $\begin{array}{c}\Delta \mathrm{T} \text { diario } \\
{\left[{ }^{\circ} \mathrm{C}\right]}\end{array}$ \\
\hline MB & 28.40 & 2.20 & 27.50 & 1.00 & & \\
MS & 28.10 & 1.30 & 28.20 & 1.20 & 27.80 & 6.40 \\
LB & 29.35 & 2.50 & 26.50 & 0.80 & & \\
LS & 29.40 & 3.00 & 27.90 & 1.50 & & \\
\hline
\end{tabular}

Relacionando los consumos con las temperaturas interiores, se puede observar que los departamentos del caso liviano necesitan consumir hasta 10 veces más que los casos del edificio másico para obtener las mismas temperaturas medias. Es decir que la envolvente liviana analizada (columnas de hormigón armado recubiertas en vidrio laminado de $6 \mathrm{~mm}$ ) en climas con condiciones térmicas extremas, no garantiza las condiciones de confort interior debido a sus escasas prestaciones como moderador climático. A causa de las ganancias internas y de la ganancia solar directa, a veces se hace necesario utilizar los sistemas de enfriamiento inclusive en otoño. En estos casos, la ganancia a través del vidrio significaría recargar estos sistemas. En consecuencia las condiciones de confort en verano se intentan alcanzar mediante energía auxiliar, que se traducen en consumos hasta 10 veces mayores respecto a los espacios interiores de envolvente másica.

\section{Invierno}

En el edificio másico (Tabla 2) las temperaturas son mayores en el caso $\mathrm{MB}$ (en $4^{\circ} \mathrm{C}$ en el estar). Asimismo, los consumos energéticos para calefacción (Figura 4b) son mayores en el caso MB con diferencias del orden del $300 \%$. Esta diferencia se explica a partir de lo observado en las entrevistas: el usuario de la vivienda MB pertenece a un mayor rango etario respecto a los habitantes del caso MS. Este factor explica la diferencia significativa de consumos entre los casos auditados. Si bien el rango etario no ha sido una variable de entrada en el presente estudio, las particularidades del usuario del caso MB hacen necesaria su consideración, para poder comprender los consumos observados en esta vivienda.

En el edificio liviano (Tabla 2 y Figura 4b) el comportamiento térmico y energético de las viviendas LB y LS es semejante (diferencias térmicas menores a $1^{\circ} \mathrm{C}$ y energéticas de 1,5 $\mathrm{kWh} / \mathrm{m}^{2}$ ) debido a un uso similar en ambas viviendas y a la tipología de torre retirada. Esta morfología expone su envolvente a todas las orientaciones, tanto bajo como sobre la copa de los árboles, teniendo mayores ganancias pero también mayores pérdidas.

Respecto a la comparación por materialidad las viviendas del caso liviano cuentan con temperaturas más elevadas respecto al caso másico, en el orden de $4^{\circ} \mathrm{C}$ a $6^{\circ} \mathrm{C}$. Esto se debe a la

46 Balter, J.; Ganem, C.; Discoli, C. 
mayor ganancia directa que ingresa por la envolvente vidriada, sumado al uso de calefacción por losa radiante durante la noche y gran parte del día.

Respecto al caso liviano, se puede ver que los consumos para calefacción en invierno son mayores a los de enfriamiento en verano, siendo que los usuarios indicaron en las entrevistas que prácticamente no es necesario el uso de calefacción central en invierno y sí señalaron el uso constante de aire acondicionado en verano, e inclusive en primavera y otoño. Esto se explica debido a que en verano el aire acondicionado se enciende en las horas de permanencia de los habitantes en la vivienda y luego se apaga; mientras que en invierno el uso de calefacción central en este tipo de edificios es constante, aunque sea mínima la temperatura fijada y los usuarios perciban correctamente que las temperaturas interiores de confort existentes se lograrían sin el uso de calefacción. Tal situación es consecuencia del subsidio económico que ejerce el estado sobre el gas natural, situación que genera confusión en la población con niveles de consumos medios y altos, y en las propias instituciones del estado; enmascarando la compleja situación de disponibilidad y uso desmedido del recurso. Los consumos residenciales de gas natural tienen una gran variación en sus demandas en función de la temperatura. A medida que la temperatura exterior disminuye, el consumo aumenta, y una vez que todos los sistemas de calefacción existentes en la residencia se han encendido, el consumo de gas tiende a estabilizarse en su valor máximo. Este es un dato de mucha relevancia y característico en la Argentina: los consumos específicos residenciales tienen una dependencia muy regular con la temperatura, y son independientes del tiempo y del contexto económico (GIL, 2006).

\section{Resultados de la simulación termo-energética}

Los resultados de las auditorias en estaciones extremas de invierno y verano mostraron comportamientos térmicos influenciados en gran medida por tres aspectos: particularidades personales (rango etario, hábitos de vestimenta, etc.), condiciones de uso y gestión de la envolvente por parte de los habitantes y por la utilización de medios mecánicos de acondicionamiento. Por esta razón se validaron los modelos mediante simulación y se mejoró la materialidad de los casos. Luego, se excluyeron las incidencias de los usuarios, se unificaron tipologíasmorfológicas y se amplió el número de casos para poder comparar las variables de altura y materialidad propias de los edificios.

Tabla 2 - Temperaturas interiores y exterior en invierno en los cuatro casos de estudio

\begin{tabular}{c|c|c|c|c|c|c}
\hline \multicolumn{6}{c}{ TEMPERATURAS DE INVIERNO } \\
\hline \multirow{3}{*}{ Casos } & \multicolumn{2}{|c}{ Estar } & \multicolumn{2}{c}{ Habitación } & \multicolumn{2}{c}{ EXTERIOR } \\
\cline { 2 - 7 } & $\begin{array}{c}\text { Temp. Media } \\
{\left[{ }^{\circ} \mathrm{C}\right]}\end{array}$ & $\begin{array}{c}\Delta \mathrm{T} \text { diario } \\
{\left[{ }^{\circ} \mathrm{C}\right]}\end{array}$ & $\begin{array}{c}\text { Temp. Media } \\
{\left[{ }^{\circ} \mathrm{C}\right]}\end{array}$ & $\begin{array}{c}\Delta \mathrm{T} \text { diario } \\
{\left[{ }^{\circ} \mathrm{C}\right]}\end{array}$ & $\begin{array}{c}\text { Temp. Media } \\
{\left[{ }^{\circ} \mathrm{C}\right]}\end{array}$ & $\begin{array}{c}\Delta \mathrm{T} \text { diario } \\
{\left[{ }^{\circ} \mathrm{C}\right]}\end{array}$ \\
\hline MB & 24.50 & 2.50 & 20.50 & 0.80 & & \\
MS & 19.85 & 1.00 & 20.10 & 1.00 & 10.40 & 13.00 \\
LB & 25.05 & 2.00 & 27.20 & 2.00 & & \\
LS & 25.90 & 2.50 & 26.70 & 1.80 & & \\
\hline
\end{tabular}

Figura 4 - Consumos mensuales para climatización

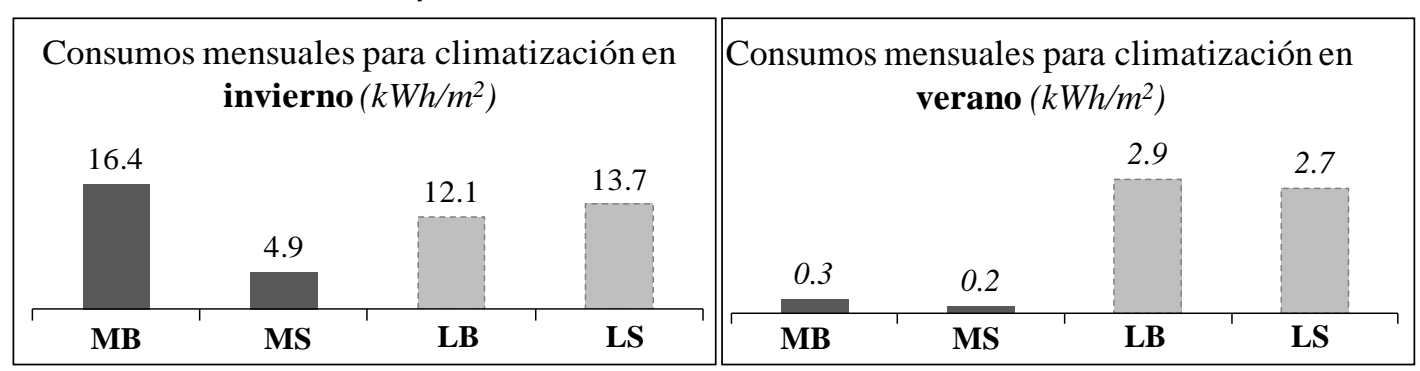

(a) Verano

(b) Invierno 


\section{Aspectos térmicos}

En el Caso Másico enverano (Figura 5) las temperaturas más bajas corresponden a la vivienda bajo la copa de los árboles ubicada en el Basamento, en un rango que se encuentra entre los $23,8^{\circ} \mathrm{C}$ y $24,7^{\circ} \mathrm{C}$. Los resultados demuestran la moderación micro-climática de la arboleda urbana que incide en las temperaturas interiores del Basamento, con diferencias del orden de los $5^{\circ} \mathrm{C}$ respecto a las viviendas de los niveles superiores.

En la tipología de Torre retirada, si bien todos los casos consienten un acceso pleno a la radiación, la exposición al intercambio convectivode la energía resulta diferente por nivel, ascendiendo en relación al aumento de altura. El $1^{\circ}$ nivel cuenta con temperaturas entre $24,8^{\circ} \mathrm{C}$ y $26^{\circ} \mathrm{C}$, el $5^{\circ}$ nivel entre $26^{\circ} \mathrm{C}$ y $27,2^{\circ} \mathrm{C}$, y la unidad de vivienda del nivel 16 , es el único caso en el que las temperaturas sobrepasan el rango de confort $^{2}$; estas se encuentran entre $\operatorname{los} 28,3^{\circ} \mathrm{C}$ y $\operatorname{los} 29,7^{\circ} \mathrm{C}$. Se observa que la media de las temperaturas aumenta $2^{\circ} \mathrm{C}$ en función de la altura.

Se observan curvas en cada nivel muy similares: las amplitudes térmicas diarias coinciden en las unidades de vivienda de la tipología de torre retirada $\left(\Delta \mathrm{T}\right.$ diario promedio del orden de $\left.1^{\circ} \mathrm{C}\right)$, mientras que en el caso bajo la protección de la arboleda las variaciones diarias son menores $(\Delta \mathrm{T}$ diario promedio de $0,7^{\circ} \mathrm{C}$ ).

En invierno (Figura 6) las mayores temperaturas se dan en la tipología de Basamento, en un rango de $19,1^{\circ} \mathrm{C}$ a $21^{\circ} \mathrm{C}$ debido a que las construcciones colindantes al Este y Oeste evitan las pérdidas térmicas. Luego, en orden descendente los departamentos del 5to nivel y 1er nivel de la tipología de Torre retirada se comportan de manera similar, con diferencias del orden de $0,5^{\circ} \mathrm{C}$ en rangos de temperaturas entre $17,5^{\circ} \mathrm{C}$ y $20,3^{\circ} \mathrm{C}$. Por último, en el nivel superior (16) se presentan las temperaturas más bajas, con un rango de $16^{\circ} \mathrm{C}$ a $18,5^{\circ} \mathrm{C}$.

En cuanto a las amplitudes térmicas diarias: en las unidades de vivienda de la tipología de torre retirada son equivalentes - del orden de $2,5^{\circ} \mathrm{C}$-, mientras que en el caso del basamento son menores, $\Delta \mathrm{T}$ de $1,5^{\circ} \mathrm{C}$ diario promedio.

En el Caso Liviano en verano (Figura 7) el caso con temperaturas más altas es el $1^{\circ}$ nivel de la tipología de Torre retirada con valores que se

${ }^{2}$ Givoni (1992) sugiere rangos de temperatura en condiciones de aire calmo entre $20^{\circ} \mathrm{C}-27^{\circ} \mathrm{C}$ para el $80 \%$ de personas en confort. Para países en vías de desarrollo, el autor sugiere la

flexibilización de $2^{\circ} \mathrm{C}$ de las temperaturas límite debido a que el habitante se encuentra adaptado a su clima. El presente trabajo adopta un rango de confort entre $18^{\circ} \mathrm{C}$ y $28^{\circ} \mathrm{C}$ teniendo en cuenta las estaciones de verano e invierno. encuentran entre $\operatorname{los} 30,2^{\circ} \mathrm{C}$ y $33,5^{\circ} \mathrm{C}$. En orden ascendente, continúa el nivel 16 , con temperaturas entre $29,4^{\circ} \mathrm{C}$ y $32,7^{\circ} \mathrm{C}$; luego el $5^{\circ}$ nivel en un rango entre los $27,90^{\circ} \mathrm{C}$ y $29,60^{\circ} \mathrm{C}$, y por último las temperaturas más bajas corresponden a la vivienda del Basamento, con valores entre $26,50^{\circ} \mathrm{C}$ y $27,80^{\circ} \mathrm{C}$. Las temperaturas superiores del $1^{\circ}$ nivel se deben a la transferencia de calor por conducción desde la planta baja. Dicho nivel cuenta con una envolvente trasparente expuesta al Norte del $100 \%$ y al Este y Oeste en un $40 \%$, por lo que las temperaturas interiores alcanzan los $37^{\circ} \mathrm{C}$ (ver línea de puntos gris en Figura 6). Asimismo, en todos los niveles de análisis las temperaturas máximas interiores se dan a las 10 hs, mientras que las máximas exteriores se registran a las 14hs. Esto se debe a la incidencia de la radiación solar en las horas de la mañana en espacios interiores con exposición de las superficies trasparentes al Nor-Este (ver Figura 2). En cuanto a las temperaturas mínimas interiores en todos los casos se dan entre las 5 y 6 de la mañana, lo cual coincide con las exteriores.

En cuanto a las amplitudes térmicas diarias los casos difieren: las temperaturas más extremas se dan en igual medida en los niveles 1 y $16(\Delta \mathrm{T}$ diario promedio de $2,30^{\circ} \mathrm{C}$ ), mientras que en el $5^{\circ}$ nivel el $\Delta \mathrm{T}$ diario promedio es de $1,20^{\circ} \mathrm{C}$ y en el caso del basamento de $0,80^{\circ} \mathrm{C}$.

En invierno (Figura 8) el edificio liviano cuenta con temperaturas dentro del rango de confort (entre $18^{\circ} \mathrm{C}$ y $28^{\circ} \mathrm{C}$ ), y a diferencia del verano, las curvas se entrecruzan. Las diferencias entre casos advierten que las temperaturas más elevadas se dan en el $1^{\circ}$ nivel de la tipología de Torre retirada, en un rango de $25,40^{\circ} \mathrm{C}$ a $19,50^{\circ} \mathrm{C}$; mientras que las más bajas se dan en el nivel 16 , entre $17,40^{\circ} \mathrm{C}$ y $23,40^{\circ} \mathrm{C}$. Ambos casos son los que mayores amplitudes térmicas diarias presentan, $\Delta \mathrm{T}$ diario promedio de $4,30^{\circ} \mathrm{C}$.

El Basamento cuenta con temperaturas entre $23,30^{\circ} \mathrm{C}$ y $21,20^{\circ} \mathrm{C}$; y el caso del $5^{\circ}$ nivel entre $22,90^{\circ} \mathrm{C}$ y $20,10^{\circ} \mathrm{C}$. Ambos departamentos son los que presentan temperaturas más estables (menor amplitud térmica diaria) en el orden de $\operatorname{los} 2^{\circ} \mathrm{C}$.

Las mayores temperaturas en el caso del $1^{\circ}$ nivel, se deben al efecto conductivo de la planta baja, en donde las temperaturas alcanzan $\operatorname{los} 30^{\circ} \mathrm{C}$ debido al "efecto invernadero", es decir que la ganancia directa dada por la cantidad de superficie vidriada de la planta baja hace que las temperaturas del $1^{\circ}$ nivel resulten superiores al resto de los casos analizados.

48 Balter, J.; Ganem, C.; Discoli, C. 
Figura 5 - Unidades de vivienda del caso másico: temperaturas interiores y exterior en verano

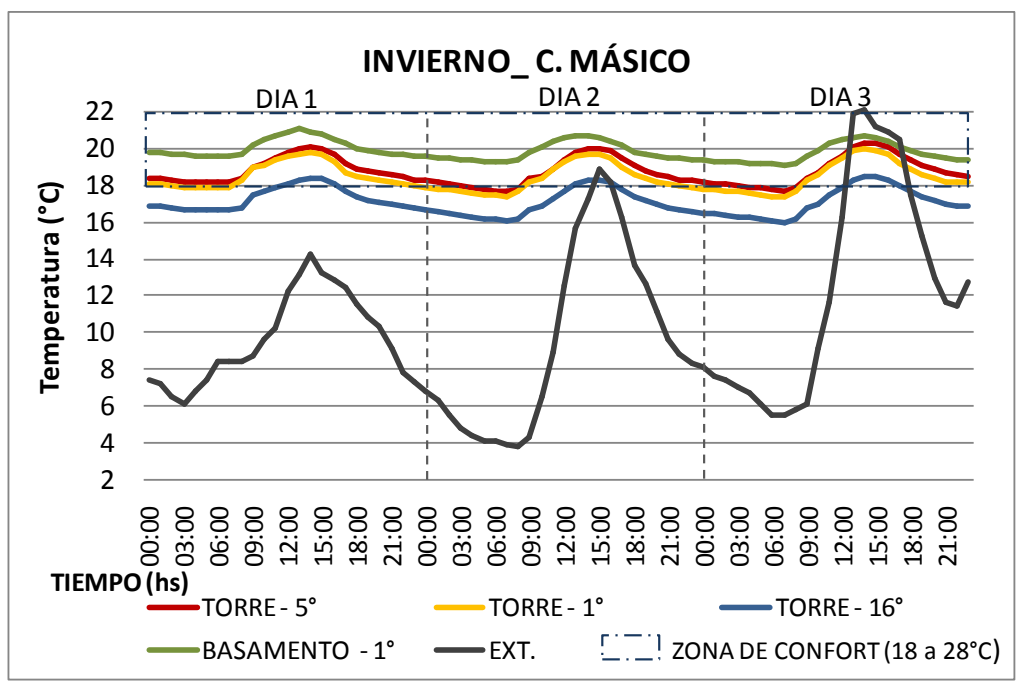

Figura 6 - Unidades de vivienda del caso másico: temperaturas interiores y exterior en invierno

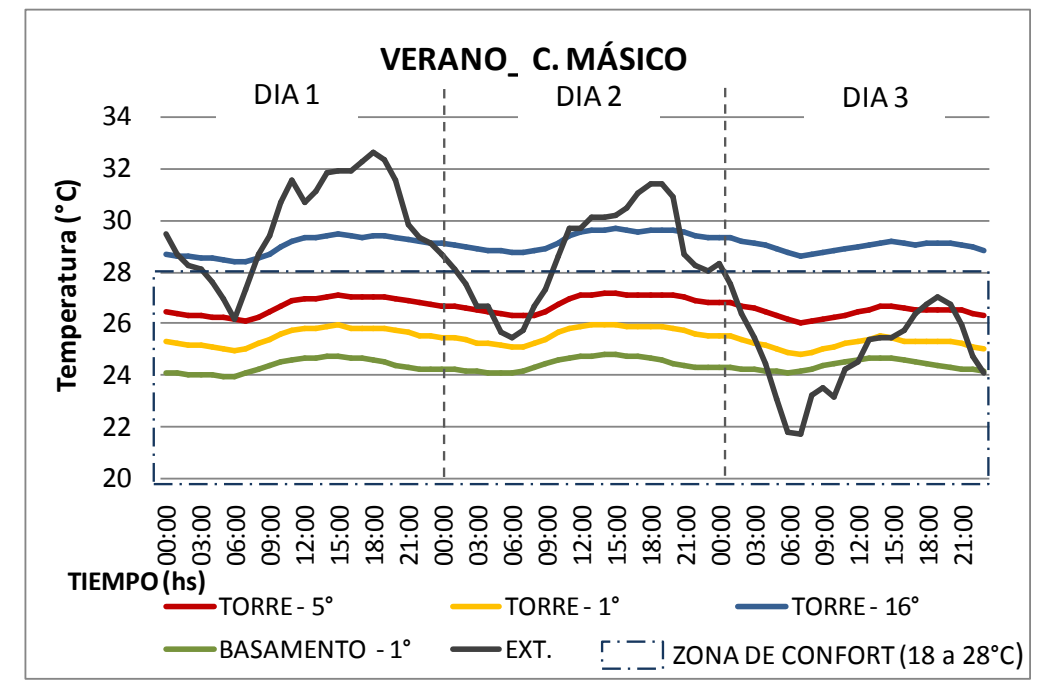

Figura 7 - Unidades de vivienda del caso liviano: temperaturas interiores y exterior en verano

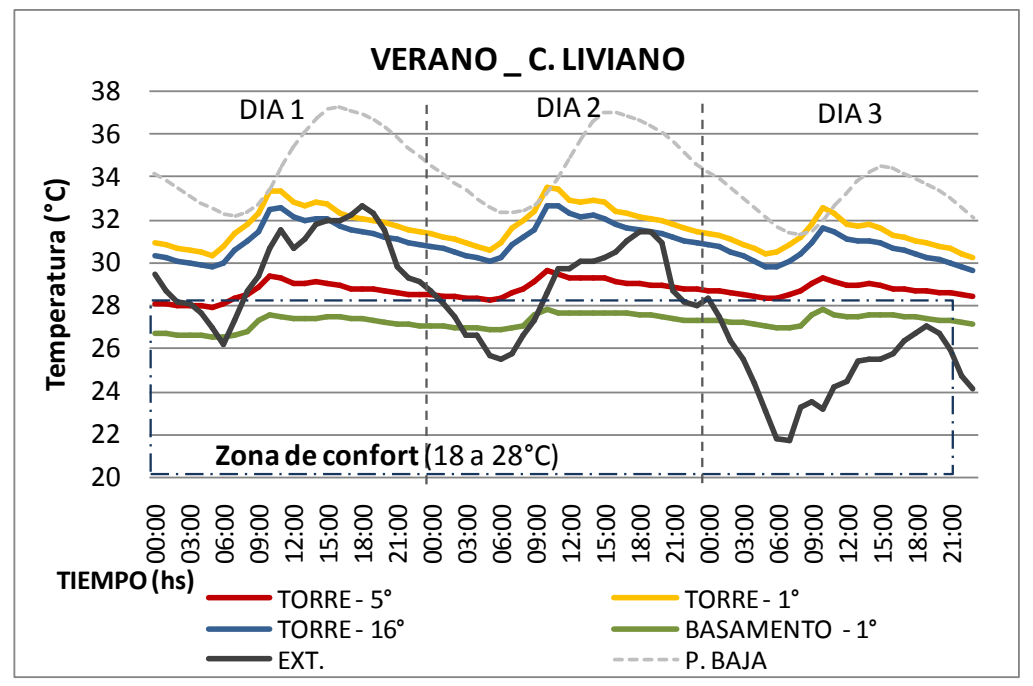


Figura 8 - Unidades de vivienda del caso liviano: temperaturas interiores y exterior en invierno

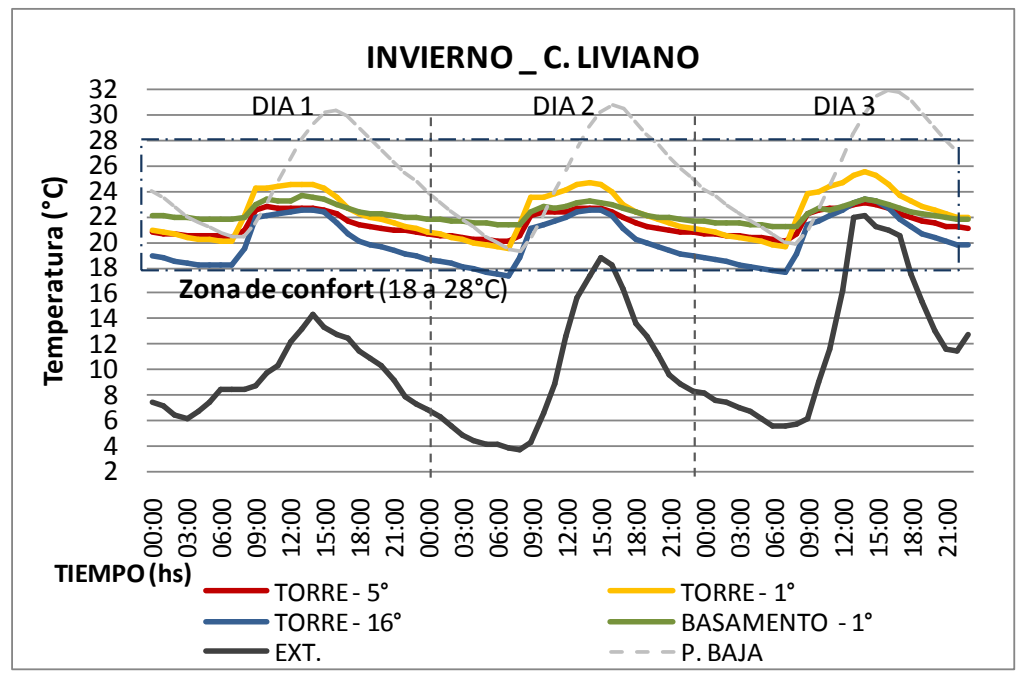

\section{Aspectos energéticos}

Se simulan los requerimientos energéticos mensuales para enfriamiento en verano y calefacción en invierno con termostatos de temperaturas constantes de $25^{\circ} \mathrm{C}$ y $20^{\circ} \mathrm{C}$ respectivamente (ver Figura 9).

En el Caso Másico en veranolos resultadosson acordes a las temperaturas interiores resultantes. El caso con mayores consumos mensuales por metro cuadrado es el nivel $16\left(2 \mathrm{kWh} / \mathrm{m}^{2}\right)$. Los consumos disminuyen a medida que se desciende en altura $\left(0.90 \mathrm{kWh} / \mathrm{m}^{2}\right.$ en el $5^{\circ}$ nivel y0.06 $\mathrm{kWh} / \mathrm{m}^{2}$ en el $1^{\circ}$ nivel), mientras que en el Basamento no se requieren consumos para enfriamiento.

De igual manera, en invierno, el caso que mayores consumos presenta es el del $16^{\circ}$ nivel, con $2.60 \mathrm{kWh} / \mathrm{m}^{2}$ mensuales, luego el del $5^{\circ}$ nivel requiere $2.20 \mathrm{kWh} / \mathrm{m}^{2}$ y el del $1^{\circ}$ nivel con $1.50 \mathrm{kWh} / \mathrm{m}^{2}$. Por último, en la vivienda de la tipología de Basamento los requerimientos energéticos disminuyen a $0.11 \mathrm{kWh} / \mathrm{m}^{2}$ mensuales.

Los consumos en el edificio másico son mayores en invierno que en verano. Las diferencias porcentuales entre ambas estaciones son: en el Basamento del orden de $100 \%$, y en la Torre del $95 \%$ en el $1^{\circ}$ nivel, $65 \%$ en el $5^{\circ}$ nivel, y del $5 \%$ en el nivel 16 .

En el Caso Liviano los resultados muestran que en verano, para mantener una temperatura de $25^{\circ} \mathrm{C}$, la vivienda con más requerimientos energéticos es la del $1^{\circ}$ nivel de la tipología en torre, con 3.20 $\mathrm{kWh} / \mathrm{m}^{2}$, debido a lo comentado anteriormente respecto a la influencia conductiva de la planta baja vidriada y la necesidad de disminuir las temperaturas en esta vivienda. En los casos del nivel 5 y 16 los consumos son del orden de $3 \mathrm{kWh} / \mathrm{m}^{2}$, mientras que, por último, la vivienda del basamento requiere $1.05 \mathrm{kWh} / \mathrm{m}^{2}$ mensuales.

En invierno, el departamento del nivel 16 requiere $1.25 \mathrm{kWh} / \mathrm{m}^{2}$ mensuales, el del $5^{\circ}$ nivel, $0.80 \mathrm{kWh} / \mathrm{m}^{2}$, y el del $1^{\circ}$ nivel $1 \mathrm{kWh} / \mathrm{m}^{2}$. En el departamento ubicado en el Basamento, la estabilidad en las temperaturas hace que no se requiera de medios mecánicos de climatización en invierno.

Los resultados en este caso muestran mayores consumos en verano que en invierno, con diferencias porcentuales en el Basamento del orden del $100 \%$, y en la Torre del $67 \%$ en el $1^{\circ}$ nivel, del $73 \%$ en el $5^{\circ}$ nivel y del $55 \%$ en el nivel 16 .

En la Figura 9 se presentan los consumos requeridos por nivel en los casos másico y liviano.

\section{Discusión de resultados}

Las auditorías térmicas y energéticas realizadas muestran comportamientos afectados en gran medida por las condiciones de uso de los habitantes. Se observa una situación mayormente crítica en las construcciones másicas en invierno, y en las construcciones livianas en verano. Los resultados del caso másico en invierno son coincidentes con otros estudios realizados en La Plata, Argentina. Estos, encuentran consumos para climatización muy diferentes en unidades de vivienda equivalentes. Los departamentos de mayor consumo relativo se correlacionan con temperaturas medias interiores superiores a las de aquellas unidades funcionales que presentan consumos inferiores (SALVETTI; CZAJKOWSKI; GÓMEZ, 2009). 
Figura 9 - Consumos mensuales para climatización en verano e invierno en viviendas a diferentes niveles de edificios másicos y livianos

\section{Consumos mensuales para climatización $(\mathrm{kwh} / \mathrm{m} 2)$}

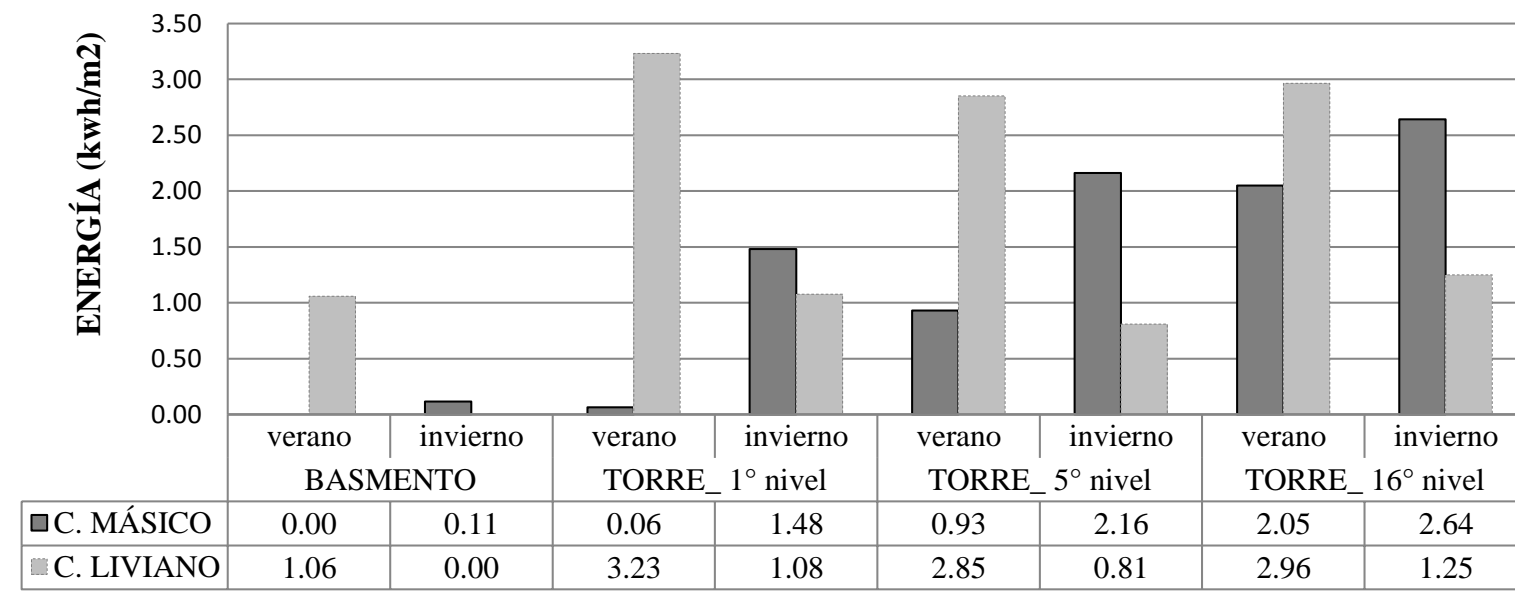

Asimismo, el caso liviano en verano presenta un comportamiento semejante a unidades de vivienda analizadas en la región central de Argentina. Al igual que los departamentos en estudio, tales viviendas aún con una importante carga de refrigeración, no logran ingresar en el área de confort. Su déficit másico, su envolvente liviana y la construcción de sus paredes divisorias internas con tabiques de bajo peso acentúan la escasez de masa de acumulación (FILIPPÍN, FLORES LARSEN, FLORES, 2007).

Respecto a los resultados excluyendo la incidencia de los usuarios y con mejoras en la materialidad los resultados indican, en el Basamento, temperaturas dentro de los rangos de confort. Tanto en edificios másicos como livianos los rangos térmicos debajo de la copa de los árboles se encuentran entre $19^{\circ} \mathrm{C}$ y $24^{\circ} \mathrm{C}$ en invierno y entre $24^{\circ} \mathrm{C}$ y $28^{\circ} \mathrm{C}$ en verano. Sin embargo, en las viviendas de la Torre (sobre la copa de los árboles) la situación difiere según la materialidad de la envolvente:

En el edificio másico las viviendas de los niveles bajos y medios (1ro y 5to) logran temperaturas dentro de los rangos de confort tanto en invierno como en verano. Sin embargo, en el nivel superior (16) las temperaturas se encuentran fuera de dicho rango, en el orden de $\operatorname{los} 2^{\circ} \mathrm{C}$, excediendo los $28^{\circ} \mathrm{C}$ en verano y por debajo de $\operatorname{los} 18^{\circ} \mathrm{C}$ en invierno. Esto evidencia la situación riesgosa y mayormente extrema de las viviendas que se encuentran en niveles superiores a los 30 metros de altura.

En cuanto al caso liviano analizado en invierno las temperaturas interiores se encuentran dentro del rango de confort (valores entre $18^{\circ} \mathrm{C}$ y $25^{\circ} \mathrm{C}$ ) sin el uso de medios mecánicos de climatización. Es decir que con la materialidad trasparente mejorada los sistemas de ganancia directa pueden lograr una gran eficiencia energética en invierno. Sin embargo, en verano la mayor superficie de envolvente transparente del edificio resulta perjudicial si no se contemplan otros sistemas de control apropiados. Las temperaturas en verano en la torre se encuentran por encima del rango de confort $\left(28^{\circ} \mathrm{C}\right)$, llegando a temperaturas interiores de hasta $34^{\circ} \mathrm{C}$, sobrepasando a las máximas exteriores (de $32,50^{\circ} \mathrm{C}$ ). Esto se explica en relación a la condición constructiva del edificio: debido al considerable espesor de los muros de $\mathrm{H}^{\circ} \mathrm{A}^{\circ}$ $(0,40 \mathrm{~m})$ y a la baja transmitancia térmica del doble vidriado $\left(K=1,8 \mathrm{~W} / \mathrm{m}^{2} \mathrm{~K}\right)$, el coeficiente global de pérdidas es bajo, por lo que la energía proveniente de la ganancia solar directa se acumula en la masa térmica del edificio. Al no tener ventilación nocturna, esta energía no disipa rápidamente al exterior durante la noche, por lo que las temperaturas interiores permanecen altas. Por este motivo es necesario incorporar sistemas pasivos de control ambiental de refrescamiento y protección a la radiación.

En cuanto a los consumos energéticos para invierno y verano, se observa que los mismos varían en relación a la materialidad: los edificios másicos van a requerir mayores consumos para climatización en invierno (con diferencias del $100 \%$ en el Basamento y entre el $40 \%$ y el $75 \%$ en la Torre), mientras que en los livianos resultarían superiores en verano (diferencias del $100 \%$ en el Basamento y entre el $30 \%$ y $98 \%$ en la Torre).

\section{Conclusiones}

El estudio a partir de mediciones realizadas in situpermitió ajustar modelos de simulación y excluir las incidencias en el uso, para poder 
trabajar con variables controladas en un entorno climático real, lo que posibilita evaluar situaciones que a veces son dificultosas de auditar en casos ocupados.

Los resultados demuestran que la construcción del Basamento en los edificios en altura en ciudades con características de oasis resulta una estrategia contundente desde el punto de vista energético y térmico. Las unidades de vivienda que se encuentran en el Basamento aprovechan la protección que brinda la arboleda urbana a la radiación incidente, dando como resultado temperaturas más bajas en verano y más elevadas en invierno debido a la menor cantidad de superficie de envolvente expuesta y a la protección de las edificaciones colindantes. En consecuencia, la necesidad de contar con medios mecánicos de climatización resulta considerablemente menor en las viviendas que se encuentran en el Basamento, entre un $70 \%$ y un $100 \%$ menos que en la Torre.

Asimismo, respecto a los aspectos urbanos, la importancia de priorizar el Basamento radica en mantener la homogeneidad edilicia en cuanto a las alturas de las construcciones que se desarrollan sobre los límites del terreno, lo cual se promueve fundamentalmente para proteger el arbolado, que en la ciudad de Mendoza posee características de valor ambiental.

No obstante, la tipología de Torre retirada resulta una tendencia en crecimiento que marca un quiebre en torno a la eficiencia energética edilicia, exponiendo cada vez más el perímetro de los edificios y quedando las envolventes con un acceso completo a la radiación solar por encima de la copa de los árboles. En este caso los espacios interiores se comportan de acuerdo a la condición climática exterior más extrema (mayor radiación, mayor velocidad de vientos) y no se aprovechan los beneficios ambientales de la Ciudad-Oasis de Mendoza.

En función de la morfología edilicia, es necesario un estudio particular de la arboleda circundante, y si el predio cuenta en la fachada con árboles con un follaje suficiente como para moderar la radiación solar, debieran aprovecharse tales condiciones en los espacios interiores mediante la obligatoriedad del Basamento. Por otra parte, resulta imprescindible considerar en el clima con las características descriptas el uso obligatorio de protecciones solares externas. De esta manera, la aplicación de normativas ambientalmente consientes orientaría a las nuevas tendencias arquitectónicas, integrar soluciones energéticamente eficientes que aseguren la habitabilidad de los espacios en el logro de unaestéticaliviana y transparente.
En cuanto a la materialidad, las viviendas de los edificios másicos demuestran un comportamiento térmico más cercano al rango de confort respecto a los edificios livianos. Esto promueve la necesidad de priorizar la masividad de las construcciones en altura en una ciudad con características climáticas áridas. Asimismo, dado el carácter sísmico de la región, muchas veces la reducción de la masa permite disminuir el costo de la estructura. Por este motivo, a la hora de proyectar, es necesaria una relación de compromiso entre la eficiencia térmica y la eficiencia estructural de la construcción.

\section{Referencias}

\section{AMERICAN SOCIETY OF HEATING, REFRIGERATING AND AIR CONDITIONING ENGINEERS. ASHRAE Handbook}

Fundamentals. Atlanta, GA, 2005.

BALARAS, C. A. The Role of Thermal Mass on the Cooling Load of Buildings: an overview of computational method. Energy and Buildings, v. 24, p. 1-10, 1996.

BALLARINI, I.; CORRADO, V. Analysis of the Building Energy Balance to Investigate the Effect of Thermal Insulationin Summer

Conditions.Energy and Building, v. 52, p. 168180, 2012.

BALTER, J.; GANEM, C.; CANTÓN, M. A. Evolución Morfológica y en Materialización en Edificios en Altura en la Ciudad de Mendoza: incidencias en el comportamiento térmico interior. Revista Área, Buenos Aires, v. 19, p. 8-25, 2013.

BOJIC, M.; YIC, F. Cooling Energy Evaluation For High-Rise Residential Buildings in Hong Kong. Energy and Buildings, v. 37, n. 4, p. 345351, 2005.

BÓRMIDA, E.N. Mendoza, Una Ciudad Oasis. Mendoza: Universidad de Mendoza, 1984.

BURATTI, C. et al. Unsteady Simulation of Energy Performance and Thermal Comfort in NonResidential Buildings. Building and

Environment, v. 59, p. 482-491, 2013.

CANTÓN, A. et al. Assessingthe Solar Resource in Forested Urban Environments. Architectural Science Review, v. 24, 2003.

CHOA, J.; YOOB, C.; KIMC, Y. Viability of Exterior Shading Devices for High-Rise Residential Buildings: case study for cooling energy saving and economic feasibility analysis. Energy and Buildings, v. 82, p. 771-785, 2014 
CZAJKOWSKI, J.; CORREDERA, C. Ahorro de Energía en Refrigeración de Edificios Para Viviendas y Propuesta de Indicadores de Eficiencia y Valores Admisibles. Avances en Energías Renovables y Medio Ambiente, v. 10, p. 09-16, 2006.

CZAJKOWSKI, J. et al. Evaluación del Confort Higrotérmico Invernal en Viviendas Unifamiliares del Gran La Plata Mediante Auditorías. Avances en Energías Renovables y Medio Ambiente, v. 16, p. 05.101-05.106, 2012.

EVANS, J. M.; SCHILLER, S. de. Evaluador Energético: método de verificación del comportamiento energético y ambiental de viviendas. Avances en Energías Renovables y Medio Ambiente, v. 5, p.07.49-07.53, 2001.

FILIPPÍN, C.; FLORES LARSEN, S.; FLORES, L. Comportamiento Energético de Verano de Una Vivienda Másica y Una Liviana en la Región Central de Argentina. Avances en Energías Renovables y Medio Ambiente, v. 11, p. 17-23, 2007.

FILIPPÍN, C.; FLORES LARSEN, S.

Comportamiento Térmico de Verano de Viviendas Unifamiliares Compactas en Condiciones Reales de Uso en Clima Templado en Argentina. Avances en Energías Renovables y Medio Ambiente, v. 14, p. 1-8, 2010.

\section{FLORES LARSEN, S. et al. SIMEDIF Para} Windows. INENCO - UNSa. 2000.

GIL, S. Gas Natural en la Argentina: presente y futuro. Revista Ciencia Hoy, v. 17, n. 101, p. 2636, 2006.

GIVONI, B. The Effective Heat Capacity in Direct Gain Buildings. Passive Solar Journal, v. 4, p. 524, 1987.

GIVONI, B. Comfort, Climate Analysis and Building Design Guidelines. Energyand Building, v. 18, p.11-23, jul. 1992.

LIU, L.; ROHDIN, P.; MOSHFEGH, B. Evaluating Indoor Environment of a Retrofitted Multi-Family Building With Improved Energy Performance in Sweden. Energy and Buildings, v. 102, p. 32-44, 2015.

LONGOBARDI, M.; HANCOCK, M. Field Trip Strategies: towards understanding the passive thermal performance of buildings using the example of a case in Naple: dogana office building. In: INTERNATIONAL CONFERENCE FOR TEACHERS OF ARCHITECTURE, 3., Oxford, 2000. Proceedingsof... Oxford, 2000.
MUNICIPALIDAD DE MENDOZA. Código de Edificación de la ciudad de Mendoza. Mendoza: Municipalidad de la Capital, 2010.

PALME, M.; ISALGUÉ, A.; COCH, H. Avoidingthe Possible Impact of Climate Change on the Built Environment: the importance of the building's energy robustness. Buildings, v. 3, p. 191-204, 2013

PENG, X. Demand Shifting With Thermal Mass in Light and Heavy Mass Commercial Buildings. Lawrence Berkeley NationalLaboratory, 2010. Disponible en:

http://escholarship.org/uc/item/9t700887. Acceso en: 10 mar. 2014.

SALVETTI, B.; CZAJKOWSKI, J.; GÓMEZ, A. Análisis del Comportamiento EnergéticoAmbiental en Torres de Vivienda en La Plata. Avances en Energías Renovables y Medio Ambiente, v. 13, p. 127-134, 2009.

SCARDUELLI, F. A.; WESTPHAL, F. S.; LAMBERTS, R. Aplicacao do Método BESTEST no Energy Plus Para Treinamento em Simulação do Desempenho Térmico de Edificacoes. In: ENCONTRO NACIONAL; ENCONTRO LATINO-AMERICANO SOBRE CONFORTO NO AMBIENTE CONSTRUÍDO, 3., Maceió, 2005. Anais... Maceió, 2005.

TERÉS-ZUBIAGA, J. et al. Energy and Economic Assessment of the Envelope Retrofitting in Residential Buildings in Northern Spain. Energy and Buildings, v. 86, p. 194-202, 2015.

TERZIOTTI, L.T.; SWEET, M. L.; MCLESKEY, J. T. Modeling Seasonal Solar Thermal Energy Storage in a Large Urban Residential Building Using TRNSYS 16. Energy and Buildings, v. 45, p. 28-31, 2012.

UNITED STATES DEPARTMENT OF ENERGY. National Department of Energy. Energy Plus Version 8.1. 2014.

VAGGE, C.; FILIPPIN, C.; CZAJKOWSKI, J. Auditorías Energéticas en Santa Rosa, La Pampa : análisis del comportamiento energético y consumo de gas natural en edificio de vivienda multifamiliar. Avances en Energías Renovables y Medio Ambiente, v. 12, p. 05.57-05.64, 2008.

\section{Agradecimientos}

Los autores agradecen al CONICET (Consejo Nacional de Investigación Científica y Tecnológica) y a los propietarios de los departamentos evaluados, por permitir la instalación de equipos de monitoreo. 


\section{Julieta Balter}

Instiruto de Ambiente, Hábitat y Energía | Consejo Nacional de Investigaciones Científicas y Técnicas | Av. Ruiz Leal, s/n, Parque General San Martín | Mendoza - Argentina | CP 5500 | Tel.: +54 (261) 524-4322 | E-mail: jbalter@mendoza-conicet.gob.ar

\section{Carolina Ganem}

Instiruto de Ambiente, Hábitat y Energía | Consejo Nacional de Investigaciones Científicas y Técnicas | Tel.: + 54 (261) $524-4309$ |

E-mail: cganem@mendoza-conicet.gob.ar

\section{Carlos Discoli}

Instituto de Investigaciones y Políticas del Ambiente Construido, Facultad de Arquitectura y Urbanismo | Universidad Nacional de La Plata; Instituto de Investigaciones en Energía no Convencional, Consejo Nacional de Investigaciones Científicas y Técnicas | Calle 47, 162 | La Plata - Argentina | CP 1900 | Tel + 54 (221) 4236587 Int. 250 | E-mail: discoli@rocketmail.com

\section{Revista Ambiente Construído}

Associação Nacional de Tecnologia do Ambiente Construído

Av. Osvaldo Aranha, $99-3^{\circ}$ andar, Centro

Porto Alegre - RS - Brasil

CEP $90035-190$

Telefone: +55 (51) 3308-4084

Fax: +55 (51) 3308-4054

www.seer.ufrgs.br/ambienteconstruido

E-mail: ambienteconstruido@ufrgs.br

54 Balter, J.; Ganem, C.; Discoli, C. 